\title{
Strongyloidiasis in Ethiopia: systematic review on risk factors, diagnosis, prevalence and clinical outcomes
}

\author{
Yitagele Terefe ${ }^{1,2}$, Kirstin Ross $^{3}$ and Harriet Whiley ${ }^{3^{*}}$ (D)
}

\begin{abstract}
Background: Strongyloidiasis is a gastrointestinal infection caused by the parasitic nematode Strongyloides stercoralis. It is estimated to infect up to 370 million people globally and is predominately found in tropical and subtropical areas of socioeconomic disadvantage.

Main body: This systematic literature review identified studies published in the last ten years on the risk factors, diagnosis, prevalence and/or clinical outcomes of strongyloidiasis in Ethiopia. The prevalence of S. stercoralis ranged from 0.2 to $11.1 \%$ in adults, $0.3 \%$ to $20.7 \%$ in children, $1.5 \%$ to $17.3 \%$ in HIV positive adults and $5 \%$ in HIV positive children. The identified studies primarily used microscopy based techniques that potentially underestimated the prevalence four fold compared with serology and PCR. Strongyloidiasis in children presents a particularly significant issue in Ethiopia as children often presented with anemia, which is associated with impaired mental and cognitive development. The most significant risk factor for strongyloidiasis was HIV status and although other risk factors were identified for helminth infections, none were statistically significant for S. stercoralis specifically. Several studies detected S. stercoralis in dogs and non-biting cyclorrhaphan flies. However, future research is needed to explore the role of these reservoirs in disease transmission.

Conclusions: This review demonstrated that strongyloidiasis is an overlooked and neglected disease in Ethiopia. There is a need for a systematic approach using a combination of molecular and serology based diagnostic methods to ascertain the true incidence and burden of strongyloidiasis in Ethiopia. Further research is also needed to break the cycle of transmission by identifying environmental reservoirs, risk factors and exploring the potential for zoonotic transfer.
\end{abstract}

Keywords: Neglected tropical disease, Soil transmitted helminth, Public health, Strongyloides stercoralis, AIDS, HIV, Anemia

\section{Multilingual abstracts}

Please see Additional file 1 for translations of the abstract into the five official working languages of the United Nations.

\section{Background}

Strongyloidiasis is caused by infection with the parasitic nematode worm, Strongyloides stercoralis, S. fuelleborni or S. fuelleborni kelli [1, 2]. Symptoms of infection range from asymptotic to non-specific gastrointestinal complaints

\footnotetext{
* Correspondence: Harriet.Whiley@flinders.edu.au

${ }^{3}$ Environmental Health, College of Science and Engineering, Flinders

University, GPO Box 2100, Adelaide, South Australia 5001, Australia

Full list of author information is available at the end of the article
}

$[2,3]$ and distinctive form of cutaneous larva migrans, larva currens [4]. The infection can remain undetected and undiagnosed for many decades $[5,6]$. However, when an infected person undergoes steroidal or immunosuppressive treatment, the worm infection undergoes hyperinfection, leading to enormous numbers of the parasite, which can then disseminate and move to other organs, a condition that is almost always fatal [7].

Strongyloidiasis has been assumed to be a disease associated with tropical or subtropical regions, and is recognised as a neglected tropical disease. However, it has been argued that strongyloidiasis should be described as a disease of disadvantage, as it is primarily a disease from developing countries and from poorer areas

(c) The Author(s). 2019 Open Access This article is distributed under the terms of the Creative Commons Attribution 4.0 International License (http://creativecommons.org/licenses/by/4.0/), which permits unrestricted use, distribution, and 
within developed countries [8]. Estimates of infection rates globally range from $50-100$ million $[3,4]$ to more than 300 million [9]. The lower estimate is likely to be an underestimate as the disease is often undiagnosed, either because it is not looked for $[3,10]$ or because of difficulties with diagnosis $[2,11]$.

Ethiopia's economy is one of the fastest growing in the world [12] although it is also one of the poorest countries in Africa [13]. The Ethiopian health care sector is currently underfunded by both global and regional standards [14] and housing and other environmental health hardware components in many areas is substandard in both rural and urban areas $[15,16]$. The lack of health care and poor environmental health conditions combine to make the country susceptible to parasitic infections, including strongyloidiasis. Here we evaluate the prevalence, risk factors and clinical outcomes for strongyloidiasis in Ethiopia reported in the literature using a systematic approach.

\section{Main text}

Materials and methods

Search strategy

The databases Scopus $(n=46)$ and Web of Science $(n=$ 44) were searched for articles written in English over the last ten years containing the keywords Strongyloides OR strongyloidiasis OR S. stercoralis OR S. fuelleborni AND Ethiopia OR Ethiopian. Figure 1 presents the systematic approach to article inclusion or exclusion. Articles were screened by reading titles and abstracts and initially excluded if they did not refer to specifically to $S$. stercoralis or if they were review articles. Article were further screened by reading abstracts and full articles and excluded if they did not investigate the prevalence of strongyloidiasis, or describe clinical presentations or potential environmental sources. As the aim of this systematic review was to provide an overview of the state of knowledge relating to strongyloidiasis in Ethiopia, all articles which met the inclusion criteria were included regardless of any flaw in study design. Limitations or bias identified are discussed in the discussion section.

\section{Results}

\section{Prevalence}

A total of 40 publications published in the last 10 years were identified that investigated the prevalence of strongyloidiasis, described clinical presentations or potential environmental sources. Table 1 presents the 27 publications that examined the prevalence of strongyloidiasis in

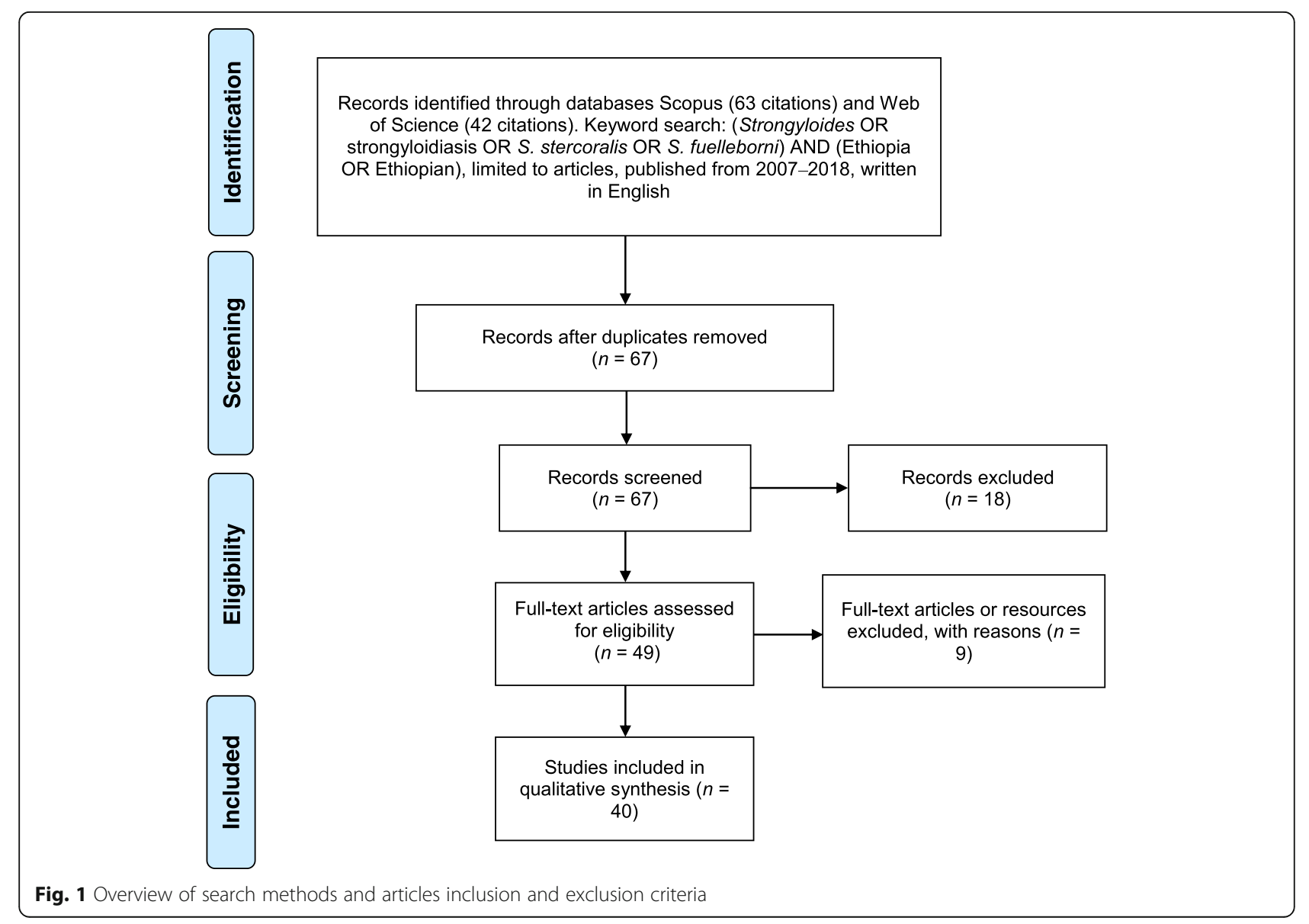


different Ethiopian populations. In HIV negative adults the prevalence of strongyloidiasis ranged from $0.2 \%$ to $11.1 \%$. Combining the results from the 16 studies investigating HIV negative adults demonstrated that the overall prevalence was $0.5 \%$ (195 positive individuals out of 36 549 tested). However, this value is skewed by the large samples size (32 191 people) and low incidence observed in the study by Ramos et al [33]. This study did not investigate the general population but rather patients from Gambo Rural Hospital presenting with diarrhea. The omission of this study increased the overall prevalence in healthy adults to $2.5 \%$. It is also important to note that in all of these studies investigating HIV negative adults, Strongyloides was detected using microscopy based stool examination techniques, which is likely to significantly underestimate the prevalence due to false negative results.

In HIV negative children the prevalence of strongyloidiasis ranged from $0.3 \%$ to $20.7 \%$ and the overall combined prevalence from 8 studies was $8.6 \%$ (298 positive out of 3453 children). However, there were significant variations in incidence depending on the diagnostic technique used. The overall prevalence in children using microscopy based stool examination techniques was $4 \%$ (from seven studies, two of which concurrently used PCR or serology) (Table 1); whereas the overall prevalence using PCR detection from stools or serology was $17.5 \%$ (three studies, two of which concurrently used microscopy). The two studies which tested using more than one detection method found $5 \%$ prevalence using microscopy compared with $17 \%$ using serology [19], and $4 \%$ using microscopy compared to $13 \%$ using PCR [26]. This suggests that microscopy based techniques could potentially underestimate prevalence by up to four fold compared with serology or PCR. This is consistent with the findings of Van Kesteren and Wojciechowski [19] that concurrently tested faeces using microscopy examination of stools and serology and found positives in $4.8 \%$ and $16.5 \%$ of patients respectively. Another study by Amor et al. reported detection of $3.5 \%$ by stool, $12.1 \%$ by Baermann and $13.4 \%$ by PCR [26]. The most common diagnostic technique by far was stool examination using the formalin-ether concentration technique, followed by the wet mount, Kato-Katz and Baermann with only one or two studies each using saline smear mount, sedimentation, agar, PCR or serology (Table 1).

The highest prevalence seen using microscopy based stool examination was in HIV positive adults. The prevalence ranged from $1.5 \%$ to $17.3 \%$ and the overall combined prevalence was $11 \%$. There was only one study of pediatric HIV patients which found the incidence to be $5 \%$ (2.5\% in highly active antiretroviral therapy [HARRT] initiated and $6.9 \%$ in HARRT naïve patients) [31].

\section{Risk factors}

The most significant risk factor for strongyloidiasis identified was HIV status (Table 1). Four studies compared the prevalence of strongyloidiasis in HIV positive and HIV negative individuals and the incidence was 5-20 times higher in HIV positive individuals compared with HIV negative [20, 41, 43, 45].

Two studies reported that the prevalence of strongyloidiasis in otherwise healthy individuals was slightly higher in males compared to females [17, 18, 33] and that higher incidence was seen in rural areas compared with urban areas [34] and in farmers [17, 18]. Three studies investigated food handlers; however, the overall prevalence was $2.7 \%$, which is not significantly higher than the general population [36, 40,44].

Several studies identified additional risk factors associated with the prevalence of intestinal parasites. Not wearing shoes, not washing hands [21,34], not trimming fingernails, or having dirt under the nails [34] were statistically significantly associated $(P<0.05)$ with intestinal helminths (including Strongyloides). Eating unwashed/ raw fruit, open field defecation, and living in a rural area was statistically significantly associated $(P<0.05)$ with intestinal parasites (including Strongyloides and other parasites) [31]. However, there were no statistically significant risk factors associated with strongyloidiasis specifically. This could be a result of the small sample sizes due to the lower prevalence of strongyloidiasis. It also highlights the need for more systematic approaches to epidemiological studies investigating the prevalence and risk factors for strongyloidiasis.

\section{Clinical manifestations}

Table 2 presents studies describing clinical manifestations of strongyloidiasis in Ethiopian individuals. The most common clinical presentation was anemia, which was observed in immunocompetent adults and children and HIV positive children. Immunocompromised individuals presented with a range of symptoms and clinical manifestations including eosinophilia, fever, vomiting, hematemesis, diarrhea, abdominal pain, bacteremia, sepsis, cough, respiratory distress, chronic obstructive pulmonary disease, hypoxemia, diffuse alveolar hemorrhage and meningitis (Table 2). Two studies reported cases of hyperinfection, one of which was fatal [51, 52]. Another study by Nadir \& Zimhony [50] reported eight cases of strongyloidiasis in AIDS patients, seven of which were fatal. The diagnosis of strongyloidiasis in these cases was complicated by negative serology results but diagnosis was confirmed through PCR and microscopy. Negative serology results were also observed in two reported cases of strongyloidiasis in immunocompetent children and diagnosis was achieved through stool examination $[47,48,50]$. 


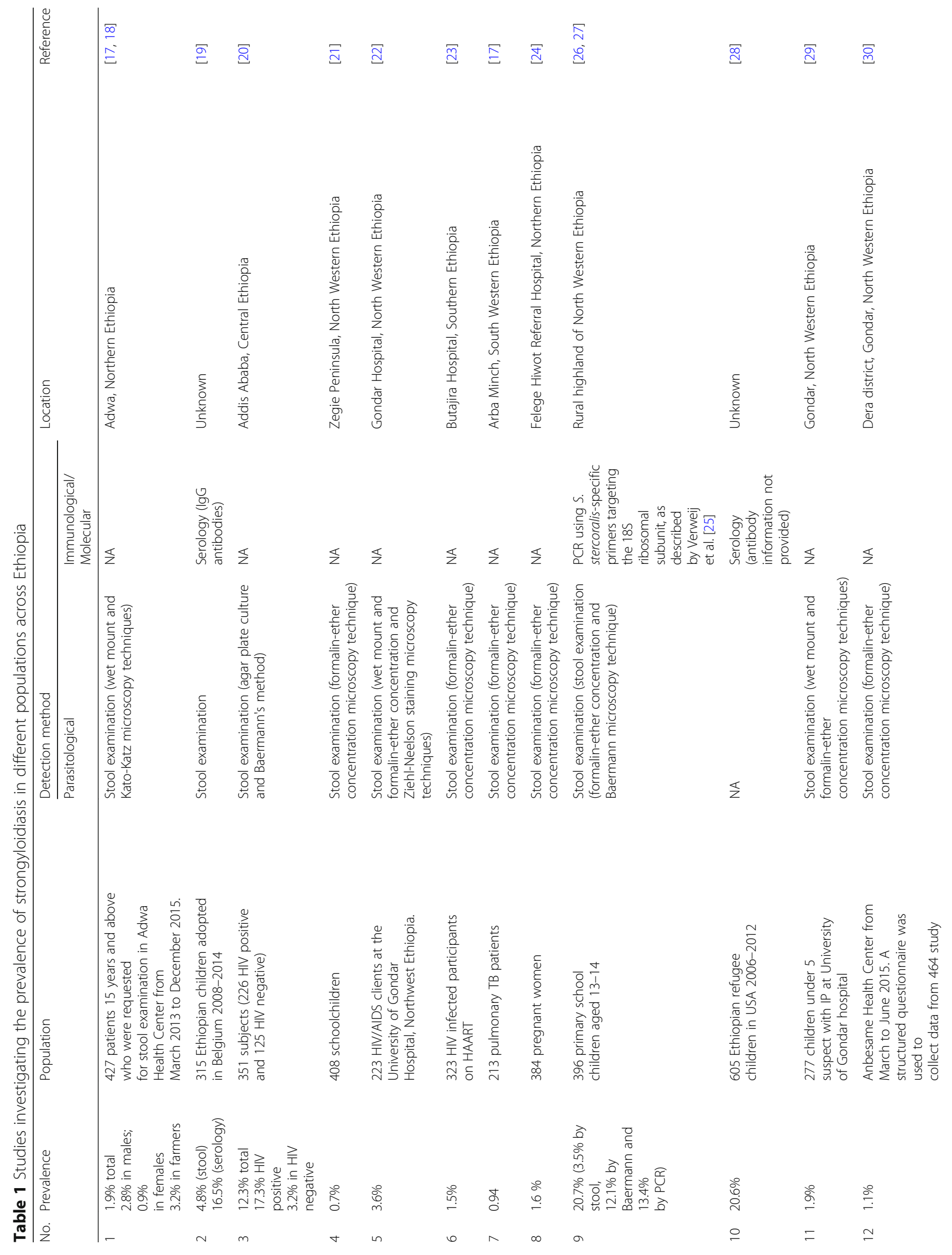




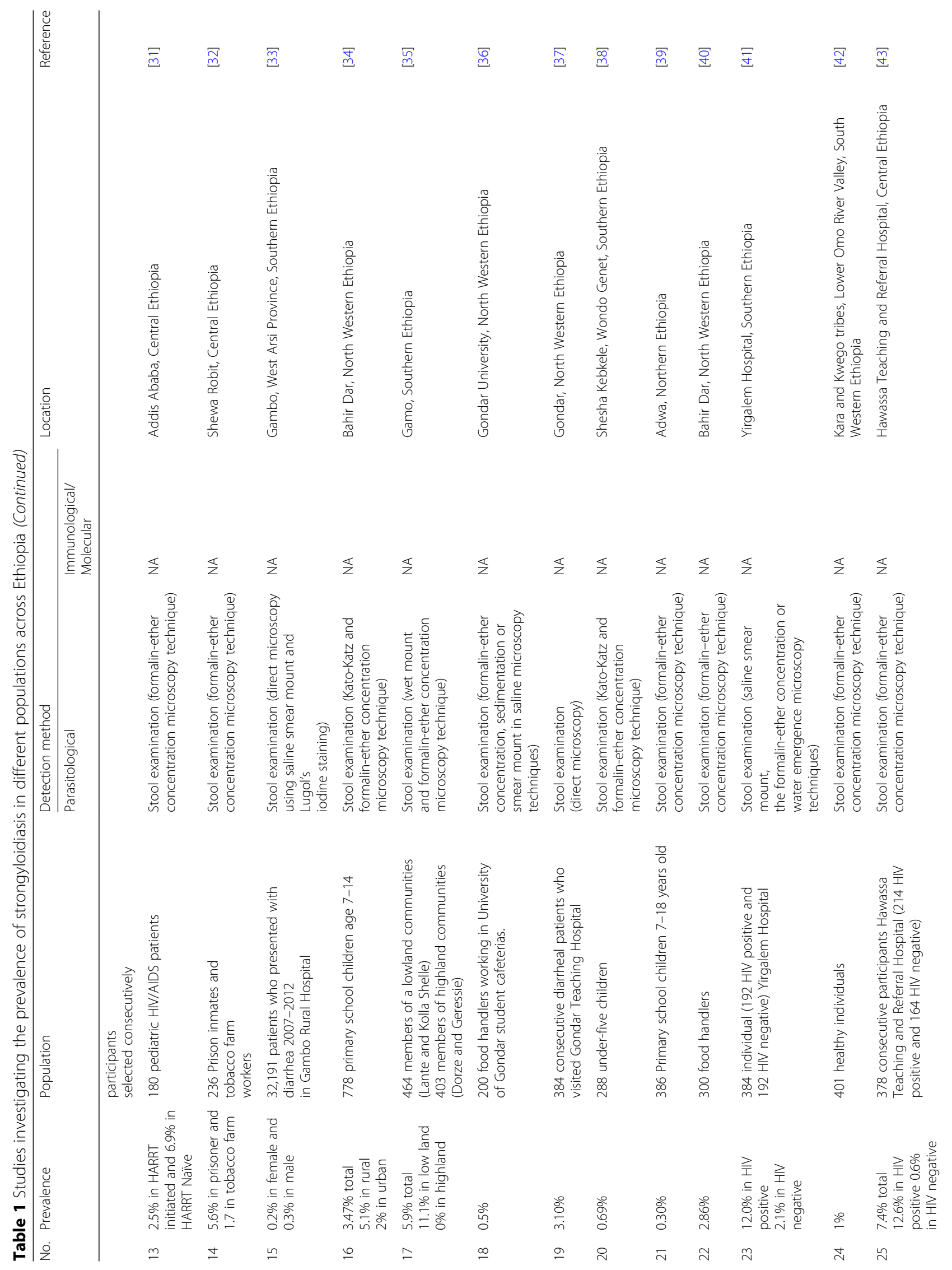




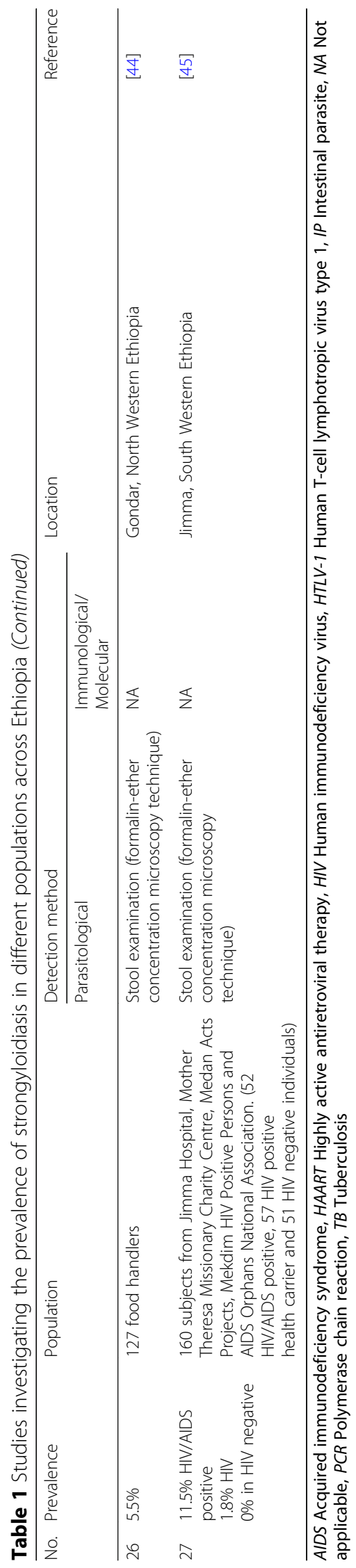




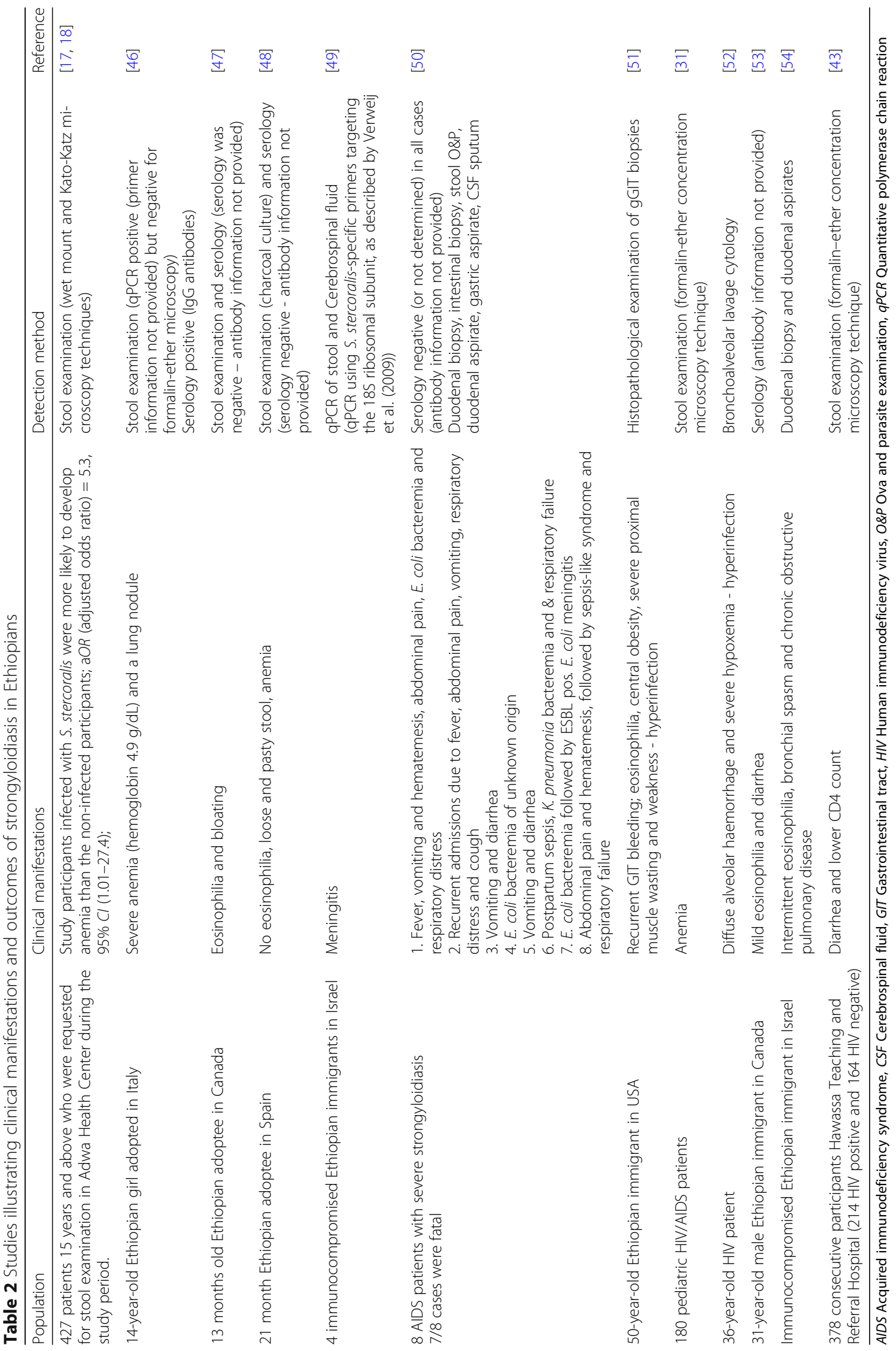




\section{Environmental sources}

There were four studies that detected $S$. stercoralis in potential environmental sources. Two studies detected $S$. stercoralis in dog faeces $[55,56]$ and two in non-biting cyclorrhaphan flies [57, 58], all of which used microscopy based stool examination techniques. A study conducted in Hawassa examined 448 dogs and found 31\% were positive for S. stercoralis [56]. Another examined 384 pet dogs and 46 stray dogs in Bahir Dar and found $30 \%$ and $46 \%$ positive respectively [55]. A study in Woreta examined 6530 non-biting cyclorrhaphan flies and found the overall presence of $S$. stercoralis to be $1.7 \%$. This included $12 \%$ of Chrysomya rufifacies, $16 \%$ Musca sorbens and 34\% Lucilia cuprina. However, Musca domestica, Calliphora vicina, Chrysomya bezziana and Wohlfahrtia magnifica were all negative [58]. These findings support a previous study conducted in Addis Ababa which examined 9550 non-biting cyclorrhaphan flies and found that $0.1-0.2 \%$ of $C$. rufifacies and $0.6 \%$ of $M$. sorbens were positive for $S$. stercoralis, whereas $L$. cuprina, M. domestica, C. vicina, Sarcophaga spp., and Wohlfahrtia spp. were all negative. Interestingly, S. stercoralis positive flies were only found in defecating areas or garbage and were not found near the butchery or market [57].

\section{Discussion}

This systematic review revealed that the prevalence of $S$. stercoralis in HIV negative Ethiopians ranged from 0.2 to $11.1 \%$ in adults and $0.3 \%$ to $20.7 \%$ in children and the calculated overall prevalence was $0.5-2.5 \%$ and $8.6 \%$ in adults and children respectively. This is comparable with other studies from Sierra Leone, Côte d'Ivoire and Sudan, which found the prevalence of $S$. stercoralis to be less than $5 \%$ [59-61]. However, it is lower compared with other studies from Angola, Nigeria and Ghana, which found the incidence of strongyloidiasis to be above $15 \%[25,62,63]$. The differences in prevalence observed in different studies may be due to different laboratory techniques, study populations, geographical factors, or economic status. In studies exploring the prevalence in children a common clinical presentation identified was anemia (Table 1). This suggests that undiagnosed strongyloidiasis in children may have significant long term consequences as iron deficiency and anemia in early childhood is associated with impaired cognition and learning ability [64]. This presents an issue of significant public health, economic and social concern for Ethiopia as infection in children can adversely affect physical, mental, education and overall societal development [65].

In this review, HIV positive individuals represented the highest risk group for $S$. stercoralis infection in Ethiopia. This finding supports several previous studies conducted across the globe $[66,67]$. It is interesting to note that the increased risk of strongyloidiasis in HIV positive individuals is not associated with an increase incidence of disseminated or hyperinfection [68]. Only one case of hyperinfection in a 36-year-old HIV positive individual was identified in this review [52]. However, a case report of strongyloidiasis in eight AIDS patients illustrated the severity of this disease in immunocompromised individuals with seven out of eight cases resulting in fatalities [50]. A complication of strongyloidiasis in HIV positive and immunocompromised individuals is the observation that serology can be falsely negative $[50,69]$. Previous global studies have also identified human T-cell lymphotropic virus type 1 Infection (HTLV-1) and alcoholism as risk factors for strongyloidiasis [70]; however, this was not seen in the Ethiopian studies. Although the absence of these risk factors could be attributed to a lack of a systematic approach to epidemiological surveillance of strongyloidiasis in Ethiopia.

There was a significant discrepancy in the prevalence observed in Ethiopia based on the diagnostic methods used in a study. Comparisons between studies found that the microscopy based techniques could potentially underestimate the prevalence by four fold compared with serology or PCR. As the majority of studies identified in this review used microscopy based techniques the true incidence of strongyloidiasis could be much higher. This supports a recent study that suggests that $S$. stercoralis infection could be overlooked and neglected in Ethiopia [27]. Similarly, a review of the global perspectives of strongyloidiasis indicated that the disease was currently underestimated in many countries, but despite this underestimation, prevalence is steadily increasing [71].

In Ethiopia, a higher prevalence of S. stercoralis was recorded in farmers and in rural populations. These findings are supported by studies conducted in Cambodia and China which identified rural populations to be at greater risk for strongyloidiasis [72, 73]. This could be due to greater environmental contamination by the larvae of $S$. stercoralis and conditions supporting their survival. However, there is a need for environmental sampling to confirm this assumption and to identify the main environmental reservoirs. Global studies have also indicated that tropical and subtropical settings in areas of economic disadvantage provide ideal conditions for transmission dynamics of $S$. stercoralis [71, 74]. This highlights the needs for research identifying the best practice in managing these environmental systems to break the life cycle and transmission dynamics of this parasite.

There were several studies which demonstrated the incidence of strongyloidiasis in Ethiopian food handlers was not greater than that of the general public. This supports the findings of a study in Malaysia which detected S. stercoralis in water samples that were used in the production of different vegetables (pegaga, kesum and water 
spinach) suggesting that vegetables and herbs may be a source of strongyloidiasis in this region [75].

Two studies demonstrated the prevalence of $S$. stercoralis in Ethiopian dogs [55, 56]. This is noteworthy given recent studies that have demonstrated the potential zoonotic transmission of $S$. stercoralis from dogs to humans $[76,77]$. This incidence of S. stercoralis in Ethiopian dogs should inform future strategies for the control of strongyloidiasis. This is particularly relevant to the argument that mass drug administration schemes to treat human should consider concomitant treatment of dogs [78]. The two studies that detected S. stercoralis in nonbiting cyclorrhaphan flies $[57,58]$ provide further insight into the potential transmission and environmental reservoirs of this parasite. This association with flies found in defecating areas and garbage supports the argument that strongyloidiasis is associated with improper sanitation hardware [74] although there is a need for further research to explore survival and transmission from these sources. It is also significant when considering the argument made by Gove [79] almost thirty years ago that the most effective approach to controlling Strongyloides infection is to control the environmental sources.

The complied information on clinical manifestations suggests that strongyloidiasis commonly presents with anemia, diarrhea, vomiting and eosinophilia. It provides a body of evidence for control campaigns or clinical management schemes to critically consider high-risk groups, such as HIV positive children, who may benefit from routine testing and/or de-worming of helminth infection [80]. Currently there are no government programs specifically targeting the surveillance, treatment and intervention of strongyloidiasis in Ethiopia. However, the Federal Ministries of Health and Education in collaboration with different international organizations deliver deworming treatments to children to tackle soil-transmitted helminthiases (intestinal worms) and schistosomiasis (bilharzia). These treatments programs are being scaled up each year and have the target of reaching 26.1 million children annually (80\% of all at-risk children) by 2020 [81]. However, to be able to evaluate the effectiveness of these deworming programs there is a need for a systematic approach using a combination of molecular and serology based diagnostic to ascertain the true incidence and burden of strongyloidiasis. Currently there is not enough information to inform medical practitioners and public health policy advisors. For example, there are limited reports from the Eastern and South Western parts of Ethiopia, although there are many hospital-based studies were reported from northern and southern part of the country which were mainly conducted by universities in the nearby areas. In addition to this, there are very few reports investigating the role of domestic animals and environmental reservoirs in the transmission of this disease.

\section{Conclusions}

This review identified that strongyloidiasis is a potentially overlooked and neglected disease in Ethiopia. Currently, there is limited information on the epidemiological situation of strongyloidiasis across the country and the studies that are available are based on microscopy techniques that underestimate the true incidence. The incidence of strongyloidiasis in children presents a significant issue for Ethiopia as infection is associated with impaired mental and cognitive development, affecting the education and societal development of an individual. In order to break the cycle of disease transmission future research is needed to identify the environmental reservoirs and routes of exposure. This includes the potential zoonotic capacity of Strongyloides from dogs and cats and information about survival within different reservoirs.

\section{Additional file}

Additional file 1: Multilingual abstracts in the five official working languages of the United Nations. (PDF $506 \mathrm{~kb}$ )

\section{Abbreviations}

AIDS: Acquired immunodeficiency syndrome; CSF: Cerebrospinal fluid; GIT: Gastrointestinal tract; HAART: Highly active antiretroviral therapy; HIV: Human immunodeficiency virus; HTLV-1: Human T-cell lymphotropic virus type 1; IP: Intestinal parasite; O\&P: Ova and parasite examination; PCR: Polymerase chain reaction; qPCR: Quantitative polymerase chain reaction; TB: Tuberculosis

\section{Acknowledgements}

Not applicable.

\section{Authors' contributions}

YT conducted analysis and wrote first draft; KR provided expert input and edited drafts; HW conceptualized project, conducted analysis and wrote first draft. All authors approve the final version.

Funding

Not applicable.

Availability of data and materials Not applicable.

Ethics approval and consent to participate Not applicable.

Consent for publication

Not applicable.

\section{Competing interests}

The authors declare that they have no competing interests.

\section{Author details}

${ }^{1}$ College of Veterinary Medicine, Haramaya University, P.O. Box 138, Dire

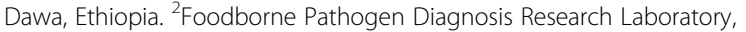
Haramaya University, P.O.Box 138, Dire Dawa, Ethiopia. ${ }^{3}$ Environmental Health, College of Science and Engineering, Flinders University, GPO Box 2100, Adelaide, South Australia 5001, Australia. 


\section{Received: 23 January 2019 Accepted: 22 May 2019}

Published online: 14 June 2019

\section{References}

1. Speare R. Identification of species of Strongyloides. In: Grove e DI, editor. Strongyloidiasis: A major roundworm infection of man. London: Taylor and Francis; 1989. p. 11-84

2. Ericsson CD, Steffen R, Siddiqui AA, Berk SL. Diagnosis of Strongyloides stercoralis infection. Clin Infect Dis. 2001;33(7):1040-7.

3. Montes M, Sawhney C, Barros N. Strongyloides stercoralis: there but not seen. Curr Opin Infect Dis. 2010;23(5):500-4.

4. Smith JD, Goette DK, Odom RB. Larva currens: cutaneous stronglyloidiasis. Arch Dermatol. 1976:112(8):1161-3.

5. Mahmoud AA. Strongyloidiasis. Clin Infect Dis. 1996;23(5):949-52 quiz 953.

6. Newberry AM, Williams DN, Stauffer WM, Boulware DR, Hendel-Paterson BR, Walker PF. Strongyloides hyperinfection presenting as acute respiratory failure and gram-negative sepsis. Chest. 2005;128(5):3681-4.

7. Kassalik M, Mönkemüller K. Strongyloides stercoralis hyperinfection syndrome and disseminated disease. Gastroenterol Hepatol (N Y). 2011;7(11):766-8.

8. Beknazarova M, Whiley H, Ross K. Strongyloidiasis: A disease of socioeconomic disadvantage. Int J Environ Res Public Health. 2016;13(5): 517-32.

9. Bisoffi Z, Buonfrate D, Montresor A, Requena-Mendez A, Munoz J, Krolewiecki AJ, et al. Strongyloides stercoralis: a plea for action. PLoS Negl Trop Dis. 2013;7(5):e2214.

10. Page W, Speare R. Chronic strongyloidiasis-Don't look and you won't find. Aust Fam Physician. 2016;45(1/2):40-4.

11. Buonfrate D, Formenti F, Perandin F, Bisoffi Z. Novel approaches to the diagnosis of Strongyloides stercoralis infection. Clin Microbiol Infect. 2015:21(6):543-52.

12. Berhanu K, Poulton C. The political economy of agricultural extension policy in Ethiopia: economic growth and political control. Develop Policy Rev. 2014;32(s2):s197-213.

13. [https://www.worldbank.org/en/country/ethiopia/overview]

14. Ali E. Health care financing in Ethiopia: Implications on access to essential medicines. Value Health Reg Issues. 2014;4:37-40.

15. Kumie A. Crowding in a traditional rural housing (Tukul) in Ethiopia. Ethiop J Health Dev. 2002;16(3):303-8.

16. Tesfaye A. Problems and prospects of housing development in Ethiopia. Prop Manag. 2007;25(1):27-53.

17. Alemu M, Kinfe B, Tadesse D, Mulu W, Hailu T, Yizengaw E. Intestinal parasitosis and anaemia among patients in a Health Center, North Ethiopia. BMC Res Notes. 2017;10(1):632

18. Gudina EK, Tesfaye M, Wieser A, Pfister HW, Klein M. Outcome of patients with acute bacterial meningitis in a teaching hospital in Ethiopia: A prospective study. PLoS One. 2018;13(7):e0200067.

19. Van Kesteren L, Wojciechowski M. International adoption from Ethiopia: An overview of the health status at arrival in Belgium. Acta Clin Belg. 2017;72(5):300-5.

20. Hailegebriel T, Petros B, Endeshaw T. Evaluation of parasitological methods for the detection of Strongyloides stercoralis among individuals in selected health institutions In Addis Ababa, Ethiopia. Ethiop J Health Sci. 2017;27(5):515-22.

21. Abdi M, Nibret $E$, Munshea A. Prevalence of intestinal helminthic infections and malnutrition among schoolchildren of the Zegie Peninsula, northwestern Ethiopia. J Infect Public Health. 2017;10(1):84-92.

22. Eshetu T, Sibhatu G, Megiso M, Abere A, Baynes HW, Biadgo B, et al. Intestinal parasitosis and their associated factors among people living with HIV at University of Gondar Hospital, Northwest-Ethiopia. Ethiop J Health Sci. 2017;27(4):411-20.

23. Gedle D, Kumera G, Eshete T, Ketema K, Adugna H, Feyera F. Intestinal parasitic infections and its association with undernutrition and CD4 T cell levels among HIV/AIDS patients on HAART in Butajira, Ethiopia. J Health Popul Nutr. 2017;36(1):15

24. Derso A, Nibret E, Munshea A. Prevalence of intestinal parasitic infections and associated risk factors among pregnant women attending antenatal care center at Felege Hiwot Referral Hospital, northwest Ethiopia. BMC Infect Dis. 2016;16(1):530

25. Verweij JJ, Canales M, Polman K, Ziem J, Brienen EA, Polderman AM, et al. Molecular diagnosis of Strongyloides stercoralis in faecal samples using realtime PCR. Trans R Soc Trop Med Hyg. 2009;103(4):342-6.
26. Amor A, Anegagrie M, Rodriguez E, Saugar JM, Arroyo A, LopezQuintana B, et al. A high prevalence of Strongyloides stercoralis found in a rural area of Amhara region, North-Western Ethiopia, by using a combination of three different diagnosis techniques. Trop Med Int Health. 2015;20:309.

27. Amor A, Rodriguez E, Saugar JM, Arroyo A, Lopez-Quintana B, Abera B, et al. High prevalence of Strongyloides stercoralis in school-aged children in a rural highland of north-western Ethiopia: the role of intensive diagnostic workup. Parasit Vectors. 2016;9(1):617.

28. Yun K, Matheson J, Payton C, Scott KC, Stone BL, Song LH, et al. Health profiles of newly arrived refugee children in the United States, 2006-2012. Am J Public Health. 2016;106(1):128-35.

29. Aleka Y, Egziabher SG, Tamir W, Birhane M, Alemu A. Prevalence and associated risk factors of intestinal parasitic infection among under five children in University of Gondar Hospital, Gondar, Northwest Ethiopia. Biomed Res Therapy. 2015;2(8):347-53.

30. Shiferaw MB, Mengistu AD. Helminthiasis: Hookworm infection remains a public health problem in Dera District, South Gondar, Ethiopia. PLoS One. 2015;10(12):e0144588

31. Mengist HM, Taye B, Tsegaye A. Intestinal parasitosis in relation to CD4+T cells levels and anemia among HAART initiated and HAART naive pediatric hiv patients in a Model ART center in Addis Ababa, Ethiopia. PLoS One. 2015;10(2):e0117715.

32. Mamo H. Intestinal parasitic infections among prison inmates and tobacco farm workers in Shewa Robit, north-central Ethiopia. PLoS One. 2014;9(6):e99559.

33. Ramos JM, Rodriguez-Valero N, Tisiano G, Fano H, Yohannes T, Gosa A, et al. Different profile of intestinal protozoa and helminthic infections among patients with diarrhoea according to age attending a rural hospital in southern Ethiopia. Trop Biomed. 2014;31(2):392-7.

34. Abera B, Alem G, Yimer M, Herrador Z. Epidemiology of soil-transmitted helminths, Schistosoma mansoni, and haematocrit values among schoolchildren in Ethiopia. J Infect Dev Ctries. 2013;7(3):253-60.

35. Wegayehu T, Tsalla T, Seifu B, Teklu T. Prevalence of intestinal parasitic infections among highland and lowland dwellers in Gamo area, South Ethiopia. BMC Public Health. 2013;13:151.

36. Dagnew $M$, Tiruneh $M$, Moges $F$, Tekeste $Z$. Survey of nasal carriage of Staphylococcus aureus and intestinal parasites among food handlers working at Gondar University, Northwest Ethiopia. BMC Public Health. 2012;12(1):837.

37. Huruy K, Kassu A, Mulu A, Worku N, Fetene T, Gebretsadik S, et al. Intestinal parasitosis and shigellosis among diarrheal patients in Gondar teaching hospital, northwest Ethiopia. BMC Res Notes. 2011:4:472.

38. Nyantekyi LA, Legesse M, Belay M, Tadesse K, Manaye K, Macias C, et al Intestinal parasitic infections among under-five children and maternal awareness about the infections in Shesha Kekele, Wondo Genet, Southern Ethiopia. Ethiop J Health Dev. 2010;24(3):185-90.

39. Legesse L, Erko B, Hailu A. Current status of intestinal schistosomiasis and soil transmitted helminthiasis among primary school children in Adwa Town, Northern Ethiopia. Ethiop J Health Dev. 2010;24(3):191-7.

40. Abera B, Biadegelgen F, Bezabih B. Prevalence of Salmonella typhi and intestinal parasites among food handlers in Bahir Dar Town, Northwest Ethiopia. Ethiop J Health Dev. 2010;24(1):46-50.

41. Getaneh A, Medhin G, Shimelis T. Cryptosporidium and Strongyloides stercoralis infections among people with and without HIV infection and efficiency of diagnostic methods for Strongyloides in Yirgalem Hospital, southern Ethiopia. BMC Res Notes. 2010;3:90.

42. Teklehaymanot T. Intestinal parasitosis among Kara and Kwego semipastoralist tribes in lower Omo Valley, Southwestern Ethiopia. Ethiop Health Dev. 2009;23(1):57-62.

43. Assefa S, Erko B, Medhin G, Assefa Z, Shimelis T. Intestinal parasitic infections in relation to HIV/AIDS status, diarrhea and CD4 T-cell count. BMC Infect Dis. 2009;9:155.

44. Andargie G, Kassu A, Moges F, Tiruneh M, Huruy K. Prevalence of bacteria and intestinal parasites among food-handlers in Gondar Town, Northwest Ethiopia. J Health Popul Nutr. 2008;26(4):451-5.

45. Mariam ZT, Abebe G, Mulu A. Opportunistic and other intestinal parasitic infections in AIDS patients, HIV seropositive healthy carriers and HIV seronegative individuals in southwest Ethiopia. East Afr J Public Health. 2008;5(3):169-73. 
46. Buonfrate D, Gobbi F, Beltrame A, Bisoffi Z. Case report: Severe anemia and lung nodule in an immunocompetent adopted girl with strongyloides stercoralis infection. Am J Trop Med Hyg. 2016;95(5):1051-3.

47. O'Neil CR, Fanella S. On lab finding, 2 vastly different causes. J Fam Prac. 2016;65(10):715-8.

48. Soriano-Arandes A, Sulleiro E, Zarzuela F, Ruiz E, Claveria I, Espasa M. Discordances between serology and culture for Strongyloides in an Ethiopian adopted child with multiple parasitic infections: A Case Report. Medicine (Baltimore). 2016;95(10):e3040.

49. Nadir E, Grossman T, Ciobotaro P, Attali M, Barkan D, Bardenstein R, Zimhony O. Real-time PCR for Strongyloides stercoralis-associated meningitis. Diagn Microbiol Infect Dis. 2016;84(3):197-9.

50. Nadir E, Zimhony O. Severe strongyloidiasis in AIDS: relative risk obscured by absolute rarity. AIDS. 2016;30(4):671-2.

51. Yee B, Chi NW, Hansen LA, Lee RR, Hoi-Sang U, Savides TJ, Vinetz JM. Strongyloides stercoralis hyperinfection syndrome presenting as severe, recurrent gastrointestinal bleeding, leading to a diagnosis of cushing disease. Am J Trop Med Hyg. 2015;93(4):822-7.

52. El-Sameed YA, Beejay N, Al MR. Diffuse alveolar haemorrhage and severe hypoxemia from Strongyloides stercoralis hyperinfection syndrome. Clin Respir J. 2015;9(4):489-92.

53. Alqarawi WA, Khan KM, Bierman AS. Weight loss · diarrhea · mild eosinophilia · Dx? J Fam Pract. 2015;64(3):174-6.

54. Malnick S, Somin M, Beilinson N, Basevitch A, Bregman G, Zimhony O. Strongyloides hyperinfection in Ethiopian immigrants in Israel. Isr Med Assoc J. 2009;11(11):660-3.

55. Abere T, Bogale B, Melaku A. Gastrointestinal helminth parasites of pet and stray dogs as a potential risk for human health in Bahir Dar town, northwestern Ethiopia. Vet World. 2013:6(7):388-92.

56. Asmare K, Mekuria S. Gastrointestinal helminthes in dogs and community perception on parasite zoonosis at Hawassa City, Ethiopia. Global Vet. 2013;11(4):432-40.

57. Getachew S, Gebre-Michael T, Erko B, Balkew M, Medhin G. Non-biting cyclorrhaphan flies (Diptera) as carriers of intestinal human parasites in slum areas of Addis Ababa, Ethiopia. Acta Trop. 2007;103(3):186-94.

58. Fetene T, Worku N. Public health importance of non-biting cyclorrhaphan flies. Trans R Soc Trop Med Hyg. 2009;103(2):187-91.

59. Gbakima A, Sahr F. Intestinal parasitic infections among rural farming communities in eastern Sierra Leone. J Afr J Med Med Sci. 1995;24(2):195-200.

60. Yapi Y, Briet OJ, Vounatsou P. Prevalence of geohelminths in savana and forest areas of Cote d'Ivoire. West Afr J Med. 2006;25(2):124-5.

61. Magambo J, Zeyhle E, Wachira T. Prevalence of intestinal parasites among children in southern Sudan. East Afr Med J. 1998;75(5):288-90.

62. de Alegría MLAR, Colmenares K, Espasa M, Amor A, Lopez I, Nindia A, et al. Prevalence of Strongyloides stercoralis and Other intestinal parasite infections in school children in a rural area of Angola: A cross-sectional study. Am J Trop Med Hyg. 2017;97(4):1226-31.

63. Agi P. Comparative helminth infections of man in two rural communities of the Niger Delta. Nigeria. West Afr J Med. 1997;16(4):232-6.

64. Bd B, McLean E, Egll I, Cogswell M. Worldwide prevalence of anaemia 19932005: WHO global database on anaemia. Geneva: World Health Organisation; 2008.

65. Stephenson LS, Latham MC, Ottesen EA. Malnutrition and parasitic helminth infections. Parasitology. 2000;121(S1):S23-38.

66. Natrajan K, Medisetty M, Gawali R, Tambolkar A, Patel D, Thorat V, et al. Strongyloidosis hyperinfection syndrome in an HIV-Infected patient: a rare manifestation of immune reconstitution inflammatory syndrome. Case Rep Infect Dis. 2018;2018:6870768.

67. Amoo JK, Akindele AA, Amoo AOJ, Efunshile AM, Ojurongbe TA, Fayemiwo SA, et al. Prevalence of enteric parasitic infections among people living with HIV in Abeokuta, Nigeria. Pan Afr Med J. 2018;30:66.

68. Siegel MO, Simon GL. Is human immunodeficiency virus infection a risk factor for Strongyloides stercoralis hyperinfection and dissemination. PLoS Negl Trop Dis. 2012;6(7):e1581.

69. Vazquez Guillamet LJ, Saul Z, Miljkovich G, Vilchez GA, Mendonca N, Gourineni $V$, et al. Strongyloides stercoralis infection among human immunodeficiency virus (HIV)-infected patients in the United States of America: A case report and review of literature. Am J Case Rep. 2017;18:339-46
70. Schär F, Trostdorf U, Giardina F, Khieu V, Muth S, Marti H, et al. Strongyloides stercoralis: global distribution and risk factors. PLoS Negl Trop Dis. 2013;7(7):e2288.

71. Puthiyakunnon S, Boddu S, Li Y, Zhou X, Wang C, Li J, Chen X. Strongyloidiasis - an insight into its global prevalence and management. PLoS Negl Trop Dis. 2014;8(8):e3018.

72. Khieu V, Schär F, Forrer A, Hattendorf J, Marti H, Duong S, et al. High prevalence and spatial distribution of Strongyloides stercoralis in rural Cambodia. PLoS Negl Trop Dis. 2014;8(6):e2854.

73. Wang C, Xu J, Zhou X, Li J, Yan G, James AA, Chen X. Strongyloidiasis: an emerging infectious disease in China. PLoS Negl Trop Dis. 2013;88(3):420-5.

74. Beknazarova M, Whiley H, Ross K. Strongyloidiasis: a disease of socioeconomic disadvantage. Int J Environ Res Public Health. 2016;13(5),

75. Zeehaida M, Zairi N, Rahmah N, Maimunah A, Madihah B. Strongyloides stercoralis in common vegetables and herbs in Kota Bharu, Kelantan, Malaysia. Trop Biomed. 2011;28(1):188-93.

76. Jaleta TG, Zhou S, Bemm FM, Schär F, Khieu V, Muth S, et al. Different but overlapping populations of Strongyloides stercoralis in dogs and humans-Dogs as a possible source for zoonotic strongyloidiasis. PLoS Negl Trop Dis. 2017;11(8):e0005752.

77. Basso W, Grandt LM, Magnenat AL, Gottstein B, Campos M. Strongyloides stercoralis infection in imported and local dogs in Switzerland: from clinics to molecular genetics. Parasitol Res. 2019;118(1):255-66.

78. Beknazarova M, Whiley H, Ross K. Mass drug administration for the prevention human strongyloidiasis should consider concomitant treatment of dogs. PLoS Negl Trop Dis. 2017:11(8):e0005735.

79. Grove DI. A history of human helminthology: CAB International; 1990.

80. Chito Orji ML, Onyire NB, Ibe BC, Ibekwe R. Effect of helminth infestationin children infected with human immunodeficiency virus (HIV). J Nepal Paediat Soc. 2017;37(1):25-30.

81. Ethiopia launches an integrated measles, vitamin A, and deworming campaign for displaced people in Gedeo Zone [https://www.afro.who.int/ news/ethiopia-launches-integrated-measles-vitamin-and-dewormingcampaign-displaced-people-gedeo]

\section{Ready to submit your research? Choose BMC and benefit from:}

- fast, convenient online submission

- thorough peer review by experienced researchers in your field

- rapid publication on acceptance

- support for research data, including large and complex data types

- gold Open Access which fosters wider collaboration and increased citations

- maximum visibility for your research: over $100 \mathrm{M}$ website views per year

At BMC, research is always in progress.

Learn more biomedcentral.com/submissions 